\title{
Removal of lead in water using activated carbon prepared from Acacia catechu
}

\author{
K Lakshmikandhan ${ }^{1}$ and A Ramadevi ${ }^{2 *}$ \\ 'Department of Chemistry, CMS College of Engineering and Technology, Coimbatore, India \\ 2Department of Chemistry, Alagappa Chettiar Government College of Engineering and Technology Karaikudi, India
}

\begin{abstract}
The adsorption of $\mathrm{Pb}$ (II) on bicarbonate-treated Acacia catechu carbon (BTACC) and commercial activated carbon (CAC) was investigated to assess the possible use of this adsorbent for $\mathrm{Pb}$ (II) removal from aqueous solutions. The results obtained from batch studies showed that $98 \% \mathrm{~Pb}$ (II) adsorption for BTACC occurs within $4 \mathrm{~h}$ of contact time, within a pH range of 4-10 and a carbon dosage of $100 \mathrm{mg}$ with initial $\mathrm{Pb}$ (II) concentration of $10 \mathrm{mg} \cdot \mathrm{L}^{-1}$, whereas for $\mathrm{CAC} 52 \% \mathrm{~Pb}$ (II) adsorption occurred within $5 \mathrm{~h}$ of contact time and a narrow range of $\mathrm{pH} 5$ and carbon dosage of $100 \mathrm{mg}$. Adsorption followed pseudosecond-order kinetics for both carbon sources, with the mechanism of adsorption being intra-particle diffusion and filmdiffusion. The best fitting adsorption isotherm for both BTACC and CAC were the Langmuir, Freundlich and Temkin models. Surface characteristics were studied using FT-IR, SEM, EDX.
\end{abstract}

Keywords: Acacia catechu, commercial activated carbon, adsorption isotherms, kinetics

\section{INTRODUCTION}

Water contains impurities of various kinds which are dissolved as well as suspended. Heavy metals are major toxic pollutants with serious health effects on humans (Inglezakis et al., 2003; Demirbas, 2008). The toxicity of heavy metals depends on the concentration of metal ions, and the nature of the organism with which it interacts. The heavy metals are the most toxic metals of widespread use in industries such as tanning, electroplating, electronic equipment, manufacturing and chemical processing plants. Lead has been recognized for centuries as a cumulative poison (Hua et al., 2012; Kadirvelu et al., 2001; WHO, 1977).

Health studies done in Poland have linked elevated levels of lead in the environment with retardation and learning disabilities of children (Groffman et al., 1992). Acute lead poisoning in humans causes severe damage to kidneys, the reproductive system, the liver, the brain and central nervous system. The neurotoxicity of lead is well known but the exact mechanisms of its toxicity are not yet understood. Disturbances in glutamate homeostasis of neural tissue and interactions of lead with calcium metabolism have been considered as potential mechanism of neurotoxicity. (Raunio et al., 2001).

Removal of $\mathrm{Pb}$ (II) by adsorption using treated granular activated carbon in both batch and column studies has been studied (Goel et al., 2005). Activated carbon developed from tamarind wood by zinc chloride activation was examined for the removal of $\mathrm{Pb}$ (II) from wastewater (Jyotikusum et al., 2009). Activated carbon prepared from marine green algae was used for adsorption of $\mathrm{Pb}$ (II) ions (Suresh Jeyakumar et al., 2014). Treatment of lead-contaminated water using activated carbon adsorbent from locally available papaya peel bio-waste has also been investigated (Sahar Abbaszadeh et al., 2016).

In the present investigation, out of various nonconventional adsorbents, modified Acacia catechu carbon is studied for its adsorption capacity for lead (II) removal from aqueous solution. This work reports the results of batch

${ }^{*}$ Corresponding author, email: ramadeviramanujam61@gmail.com Received 11 June 2018; accepted in revised form 4 June 2019 studies on the removal of lead (II) from aqueous solution by adsorption, using bicarbonate-treated Acacia catechu carbon (BTACC) as an adsorbent. Various parameters, such as equilibrium time, $\mathrm{pH}$ and dosage of adsorbent, and adsorption isotherms were studied. Commercial activated carbon (CAC) procured from the market was used for evaluation purposes.

\section{MATERIALS AND METHODS}

\section{Preparation of bicarbonate-treated Acacia catechu carbon (BTACC)}

Acacia catechu seeds were collected, washed with distilled water and dried at $110^{\circ} \mathrm{C}$. Seeds were then broken mechanically into small particles and sieved to 20-50 ASTM mesh size. Then the material was treated with concentrated sulphuric acid with a weight ratio of 1:1 and kept in an air oven at 150 $\pm 5^{\circ} \mathrm{C}$ for $24 \mathrm{~h}$. The carbonized material was washed well with distilled water to remove the free acid and dried at 105 $\pm 5^{\circ} \mathrm{C}$. Then it was soaked in $1 \%$ sodium bicarbonate solution until the effervescence ceased, and finally soaked in sodium bicarbonate solution for $24 \mathrm{~h}$ to remove any residual acid. The material was then washed with distilled water, and dried at 105 $\pm 5^{\circ} \mathrm{C}$ (BTACC). Preliminary studies were carried out with raw Acacia catechu seed, sulphuric acid treated Acacia catechu seed carbon and sulphuric acid treated Acacia catechu seed modified by $1 \%$ sodium bicarbonate solution (BTACC) for $\mathrm{Pb}$ (II) removal. Based on removal efficiency, BTACC was chosen for further studies. The characteristics of BTACC and commercial activated carbon (CAC) were investigated and are summarized in Table 1. Subsequent experiments were carried out with BTACC and the performance of the carbon was evaluated by using CAC obtained from SD Fine Chemicals, considering the same particle size of 20-50 ASTM.

\section{Batch experiment}

A stock solution of $\mathrm{Pb}$ (II) was prepared by dissolving $0.3997 \mathrm{~g}$ of anhydrous lead nitrate in $100 \mathrm{~mL}$ distilled water containing $0.1 \mathrm{~mL}$ of concentrated nitric acid (to prevent hydrolysis) and 
diluting it to $250 \mathrm{~mL}$. This solution was diluted further to 100 $\mathrm{mL}$ of $\mathrm{Pb}$ (II) solution of desired concentration adjusted to a desired $\mathrm{pH}$ in reagent bottles of $300 \mathrm{~mL}$ capacity. A known amount of BTACC and CAC were added and $\mathrm{pH}$ was adjusted using dilute hydrochloric acid or sodium hydroxide solutions. All chemicals used were of analytical grade and were obtained from Ranbaxy, $\mathrm{BDH}$. The solutions were agitated and the filtrate was analysed for lead content (APHA, AWWA, 1973). Maintaining the dosage of carbon at a constant level, the adsorption isotherm for $\mathrm{Pb}$ (II) with different initial

Table 1. Characteristics of bicarbonate-treated Acacia catechu carbon (BTACC) and commercial activated carbon (CAC)

\begin{tabular}{llcc}
\hline Sl. No. & Control test & BTACC & CAC \\
\hline 1 & Bulk density $\left(\mathrm{g} \cdot \mathrm{L}^{-1}\right)$ & 0.7656 & 0.7581 \\
2 & Moisture (\%) & 9.14 & 7.32 \\
3 & Ash (\%) & 2.15 & 20.94 \\
4 & Solubility in water (\%) & 1.21 & 0.453 \\
5 & Solubility in $0.25 \mathrm{~N} \mathrm{HCl}(\%)$ & 5.19 & 2.03 \\
6 & $\mathrm{pH}$ & 4.84 & 8.35 \\
7 & Decolorizing power $\left(\mathrm{mg} \cdot \mathrm{g}^{-1}\right)$ & 9.0 & 4.5 \\
8 & Phenol number & 68 & 51 \\
9 & Ion exchange capacity $\left(\mathrm{m} \mathrm{equiv} \cdot \mathrm{g}^{-1}\right)$ & 0.6024 & $\mathrm{Nil}$ \\
10 & Surface area $\left(\mathrm{m}^{2} \cdot \mathrm{g}^{-1}\right)$ & 326 & 205 \\
11 & Iron (\%) & 6.21 & 4.15 \\
12 & Porosity (\%) & 2.1 & 1.95 \\
\hline
\end{tabular}
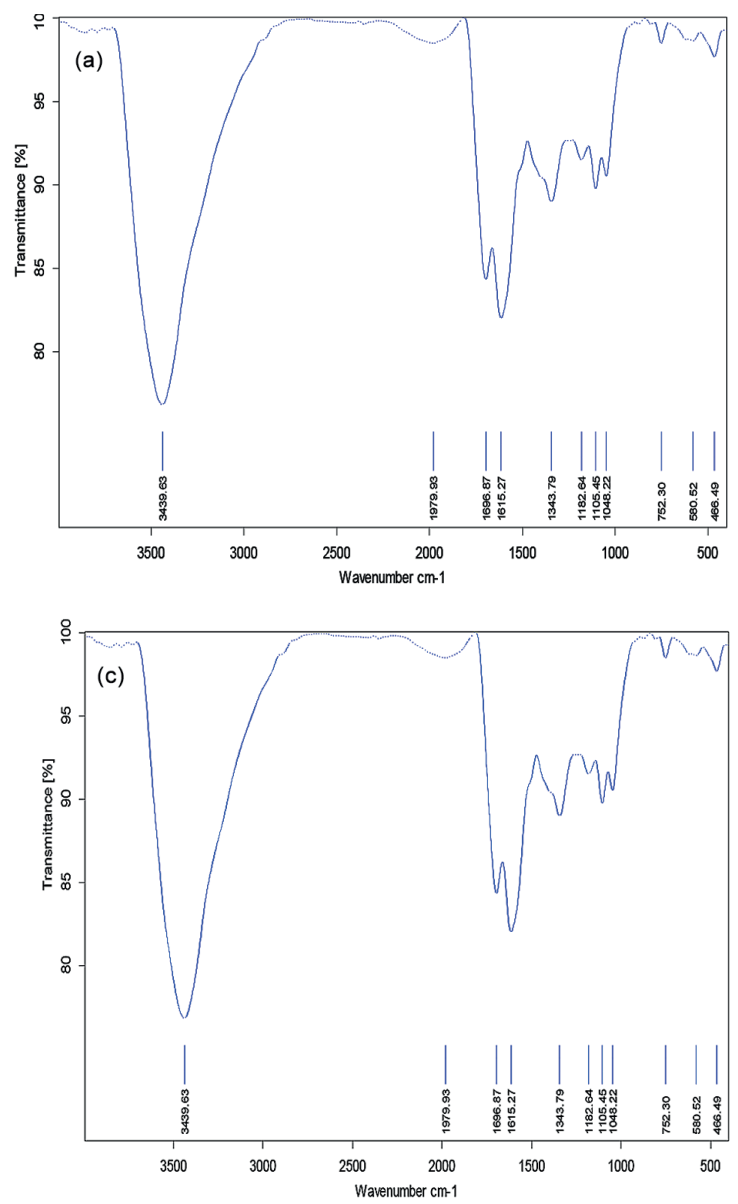

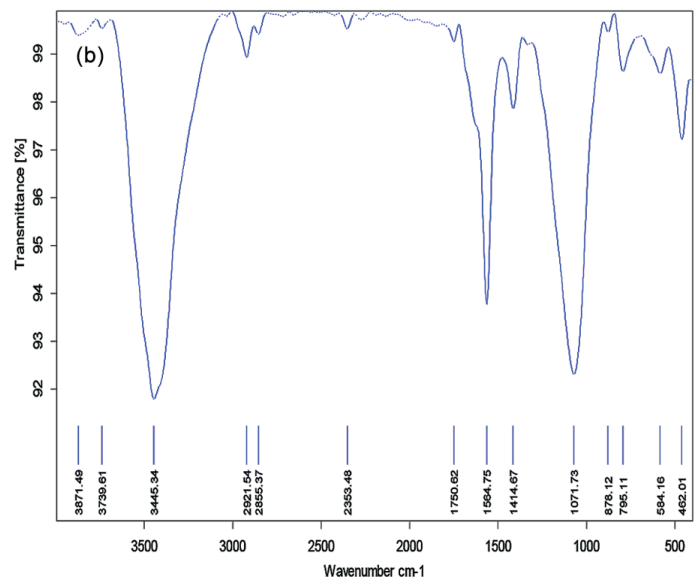

concentrations was studied. For $\mathrm{pH}$ effect, $10 \mathrm{mg} \cdot \mathrm{L}^{-1}$ of $\mathrm{Pb}$ (II) for BTACC and CAC with a dosage of $100 \mathrm{mg} \cdot 100 \mathrm{~mL}^{-1}$ were used. In order to correct for any adsorption of $\mathrm{Pb}$ (II) due to the container, control experiments were carried out without adsorbent and there was negligible adsorption by the container wall.

\section{RESULTS AND DISCUSSION}

Examination of carbon characteristics in Table 1 shows that the BTACC has higher moisture content than CAC. Higher moisture content of BTACC suggests that the acid treatment made the carbon more porous and BTACC has lower ash content than CAC, which indicates more carbon content. The surface area is found to be greater for BTACC than CAC.

\section{Surface characterization of activated carbon}

Fourier transform infrared spectroscopic analysis (FT-IR)

Fourier transform infrared spectroscopy (FT-IR) studies were used to identify the functional groups present on the surface of the adsorbent. FT-IR spectra of BTACC and CAC are shown in Fig. 1a-d. This shows the presence of poly functional groups. The strong absorption peak at $3445 \mathrm{~cm}^{-1}$, is due to the -OH stretching vibration due to inter- and intra-molecular

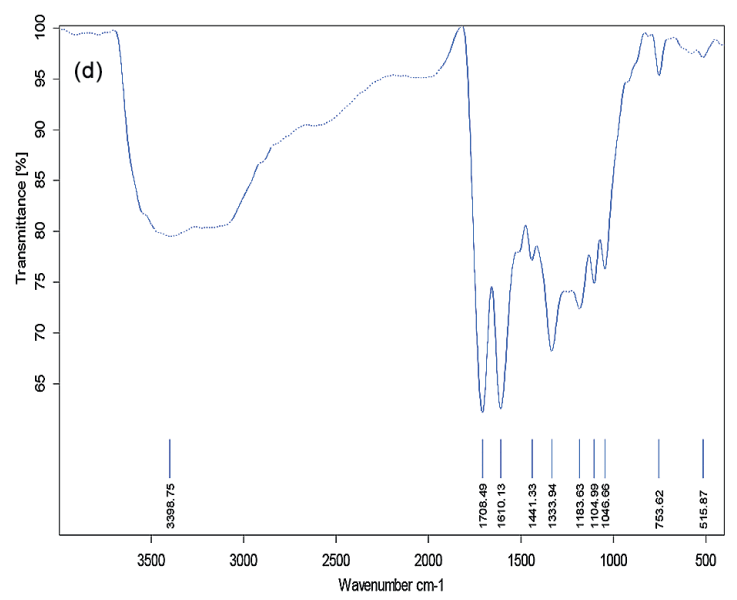

Figure 1. (a, b) FT-IR spectra of before and after adsorption of Pb (II) ions on BTACC; (c, d) FT-IR spectra of before and after adsorption of $\mathrm{Pb}$ (II) ions on CAC 
hydrogen bonding of alcohols, phenols and carboxylic acids. The peaks at $2928 \mathrm{~cm}^{-1}, 2362 \mathrm{~cm}^{-1}$ and $1698 \mathrm{~cm}^{-1}$ are due to the $\mathrm{C}-\mathrm{H}$ stretching, $\mathrm{C} \equiv \mathrm{C}$ stretching and $-\mathrm{CO}$ stretching vibration of ether. The presence of sulphonic acid groups is confirmed by the peak at $1343 \mathrm{~cm}^{-1}$. From the observations it is evident that some of the peaks shift or become weak indicating the incorporation of heavy metal ion $\mathrm{Pb}$ (II) within the adsorbent through the interaction of the active functional group after adsorption.

\section{Scanning electron microscopy (SEM)}

SEM was used to study the morphology and surface characteristics of the adsorbent material (Tharanitharan et al., 2009). Adsorption capacity depends on the chemical composition of the adsorbent. The pore size, shape and volume also play an important role in the adsorption process. The SEM images of the adsorbent BTAAC and CAC before and after adsorption of $\mathrm{Pb}$ (II) ions are given in Fig. 2a-d. This image shows the presence of isolated pores and uneven cavities before and after adsorption. The irregular and porous surface activated carbon could be observed. On the basis of this fact, it can be concluded that BTACC presents an adequate morphology for $\mathrm{Pb}$ (II) adsorption (Deepak et al., 2013).

\section{Energy dispersive $X$-ray analysis (EDX)}

Energy dispersive X-ray analysis (EDX) technique is used for elemental analysis or chemical characterization of a sample in conjunction with scanning electron microscopy (SEM). To resolve the elemental content, the electron-beam strikes the surface of a conducting sample (SEM). The EDX spectra of the $\mathrm{Pb}$ (II) ion adsorbed on BTACC and CAC show peaks for metal ions in addition to the other cations, confirming the adsorption of $\mathrm{Pb}$ (II) ions on the surface of the adsorbent (Fig. $3 \mathrm{a}-\mathrm{d}$ ).

\section{Effect of agitation time}

The effect of agitation time on the removal of $\mathrm{Pb}$ (II) by BTACC and CAC is shown in Fig. 4. Percentage removal increases with time and attains equilibrium at $3 \mathrm{~h}$ for BTACC and $4 \mathrm{~h}$ for $\mathrm{CAC}$ for an initial concentration of $10 \mathrm{mg} \cdot \mathrm{L}^{-1}$ of $\mathrm{Pb}$ (II). However, $4 \mathrm{~h}$
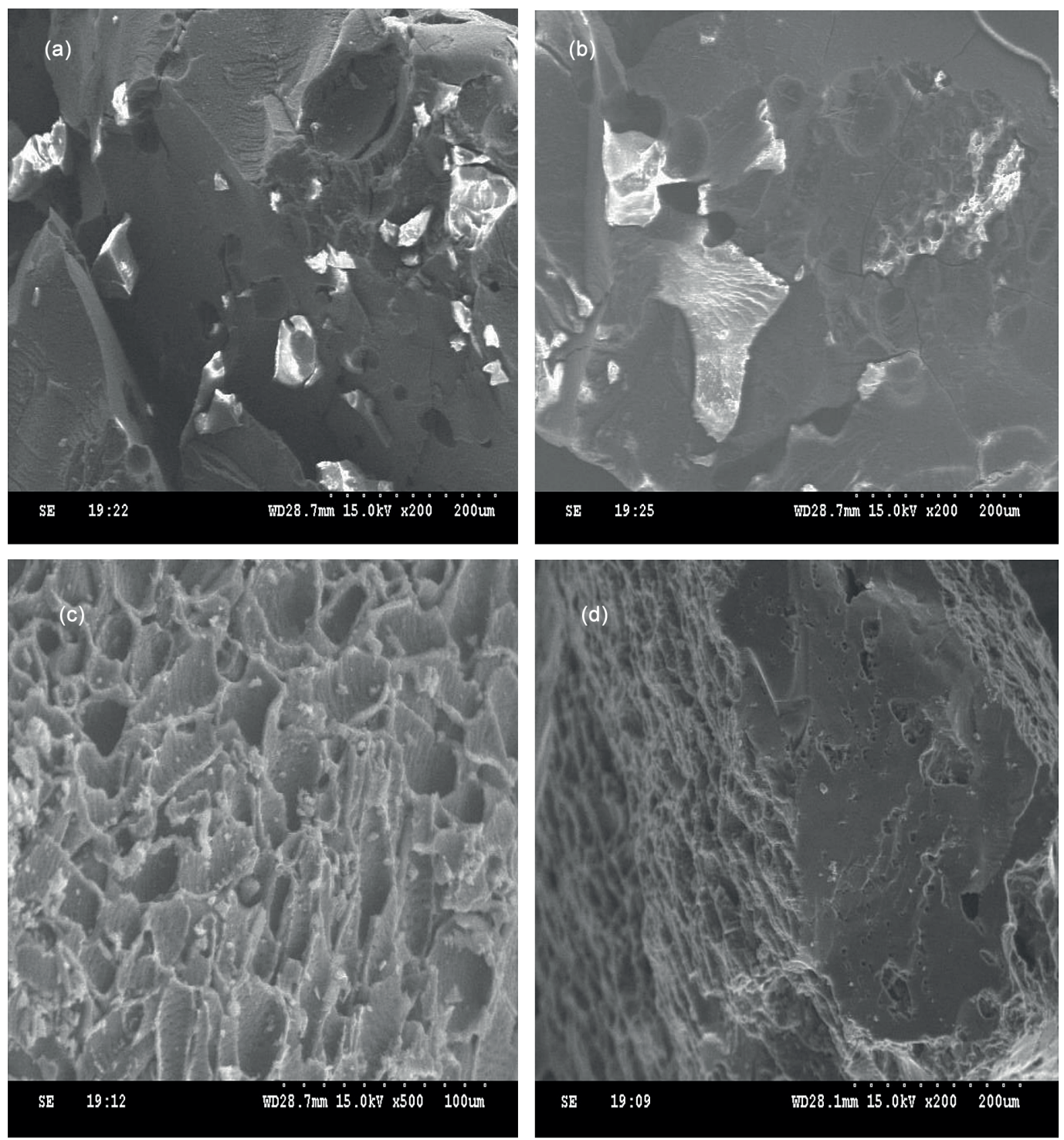

Figure 2. $(a, b)$ SEM images before and after adsorption of $\mathrm{Pb}$ (II) ions on BTACC; $(c, d)$ SEM images before and after adsorption of $\mathrm{Pb}$ (II) ions on CAC 
and $5 \mathrm{~h}$ shaking time was maintained for BTACC and CAC, respectively, for further studies. It was found that BTACC showed $98 \%$ lead (II) removal whereas CAC showed 52\% removal for a carbon dosage of $100 \mathrm{mg} \cdot 100 \mathrm{~mL}^{-1}$ of $\mathrm{Pb}$ (II) ion solution of initial concentration of $10 \mathrm{mg} \cdot \mathrm{L}^{-1}$.

\section{Effect of carbon dosage}

Figure 5 represents the removal of $\mathrm{Pb}$ (II) as a function of carbon dosage for both BTACC and CAC. It was shown that a minimum carbon dosage of $100 \mathrm{mg}$ of BTACC was required for $98 \%$ removal of $\mathrm{Pb}$ (II) from a $10 \mathrm{mg} \cdot \mathrm{L}^{-1}$ lead solution. However, a maximum removal of $52 \%$ was observed for CAC with a carbon dosage of $100 \mathrm{mg}$ for the same concentration of $\mathrm{Pb}$ (II). This shows that BTACC was nearly 2 times more efficient than $\mathrm{CAC}$ for $\mathrm{Pb}$ (II) removal.

\section{Effect of pH}

Figure 6 shows the effect of initial $\mathrm{pH}$ on the removal of $\mathrm{Pb}$ (II) by BTACC and CAC. It is clear that BTACC is effective for the quantitative removal of $\mathrm{Pb}$ (II) over the $\mathrm{pH}$ range of 4.0-10.0. However, for CAC the quantitative removal was only at a narrow $\mathrm{pH}$ of 5 . The influence of $\mathrm{pH}$ on lead removal can likely be explained as follows. At lower $\mathrm{pH}$, a higher concentration of hydrogen ions present in the mixture competes with the positively charged metal ion for the adsorption sites, resulting in the reduced uptake of metal ions. As the $\mathrm{pH}$ increases, the concentration of $\mathrm{Pb}$ (II) ions remains constant and therefore the uptake of metal ions can be explained as $\mathrm{H}^{+}-\mathrm{Pb}^{2+}$ exchange

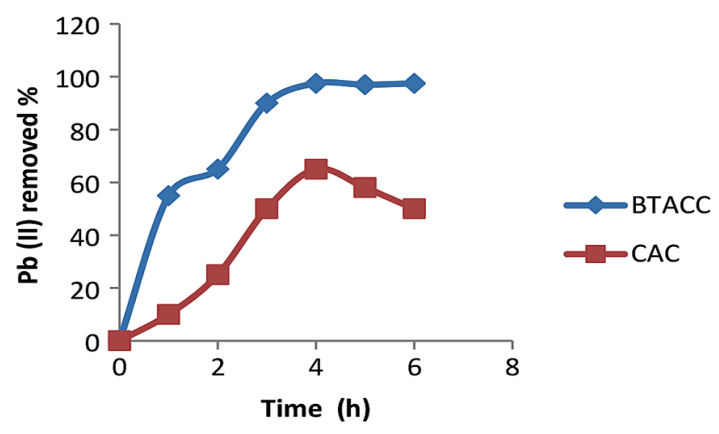

Figure 4. Effect of contact time for the removal of $\mathrm{Pb}$ (II) by BTACC and $C A C(\mathrm{pH}=5.0)$

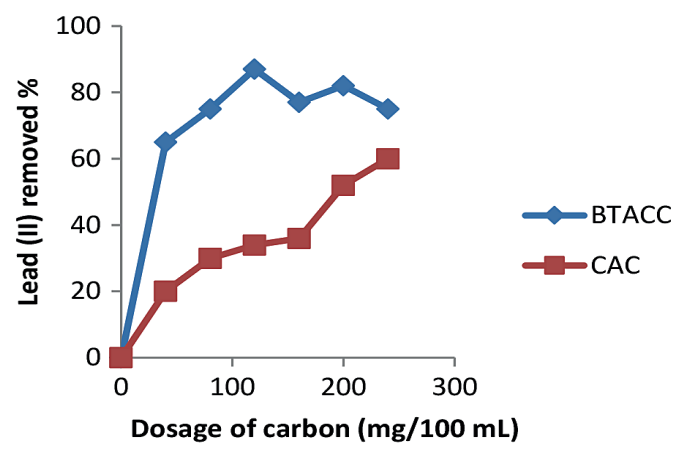

Figure 5. Effect of carbon dosage on the removal of $\mathrm{Pb}$ (II) by BTACC and $\mathrm{CAC}(\mathrm{pH}=5.0)$, equilibrium time $=3 \mathrm{~h}$, concentration of $\mathrm{Pb}(\mathrm{II})=$ $10 \mathrm{mg} \cdot \mathrm{L}-1$ for $C A C$
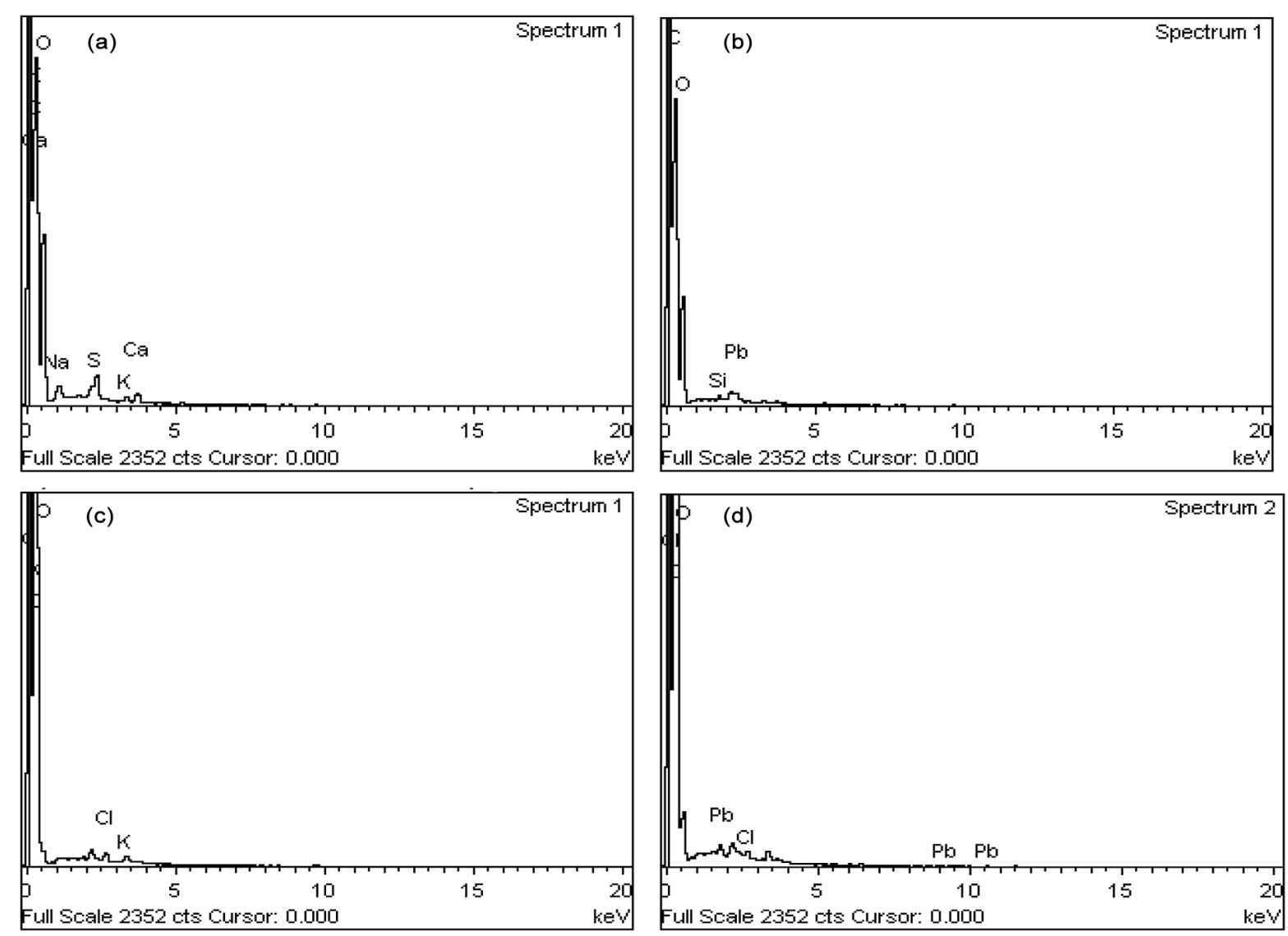

Figure 3. $(a, b)$ Edx pattern of before and after adsorption of Pb (II) ions on BTACC; $(c, d)$ Edx pattern of before and after adsorption of $\mathrm{Pb}$ (II) ions on $\mathrm{CAC}$ 


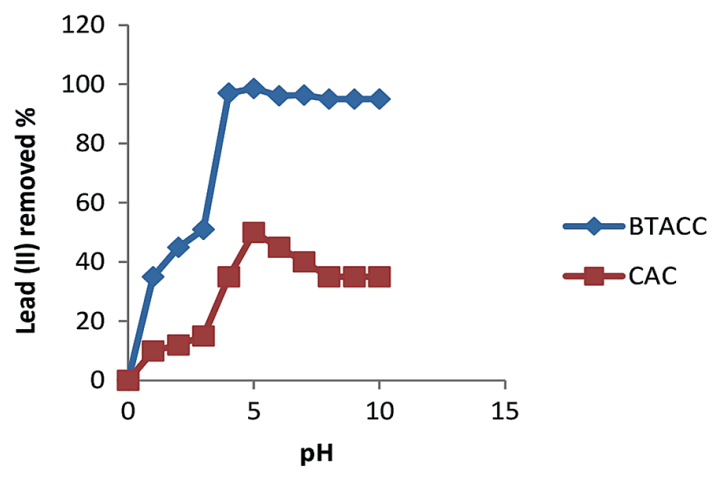

Figure 6. Effect of $\mathrm{pH}$ on the removal of $\mathrm{Pb}$ (II) by BTACC and CAC

reaction. The major mechanism of adsorption of $\mathrm{Pb}^{2+}$ seems to be ion exchange. Furthermore, a pure carbon surface is considered to be non-polar, but in actual practice some carbonoxygen complexes, such as $\mathrm{C}_{\mathrm{x}} \mathrm{O}, \mathrm{CO}_{\mathrm{x}}$ and $\mathrm{C}_{\mathrm{x}} \mathrm{O}_{2}$ are usually present which render the surface slightly polar. The interaction of the above groups with aqueous phase may lead to the following hydrolytic reactions:
$\mathrm{C}_{\mathrm{x}} \mathrm{O}+2 \mathrm{H}_{2} \mathrm{O}$
$\mathrm{CO}_{\mathrm{x}}+\mathrm{XH}_{2} \mathrm{O}$
$\mathrm{C}_{\mathrm{x}} \mathrm{O}_{2}+\mathrm{H}_{2} \mathrm{O}$

$$
\begin{aligned}
& \mathrm{CxOH}_{2}^{2+}+2 \mathrm{OH}^{-} \\
& \mathrm{C}(\mathrm{OH})_{\mathrm{x}}^{+}+\mathrm{XOH}^{-}
\end{aligned}
$$$$
\mathrm{C}_{\mathrm{x}} \mathrm{O}^{2+}+2 \mathrm{OH}^{-}
$$

Since BTACC was prepared upon treatment with sulphuric acid and sodium bicarbonate, groups such as $\mathrm{C}_{\mathrm{x}} \mathrm{ONa}^{2+}, \mathrm{C}_{\mathrm{x}} \mathrm{ONa}^{+}, \mathrm{C}_{\mathrm{x}} \mathrm{SO}_{3} \mathrm{H}$ and $\mathrm{C}_{\mathrm{x}} \mathrm{SO}_{3} \mathrm{Na}$ are also assumed to be present. $\mathrm{Na}^{+}$ions in the above groups are also exchanged with $\mathrm{H}^{+}$in the medium as follows:
$\mathrm{C}_{\mathrm{x}} \mathrm{ONa}^{+}+\mathrm{H}^{+}$
$\mathrm{C}_{\mathrm{x}} \mathrm{O} \mathrm{H}^{+}+\mathrm{Na}^{+}$
$\mathrm{C}_{\mathrm{x}} \mathrm{ONa}^{2+}+2 \mathrm{H}^{+}$
$\mathrm{C}_{\mathrm{x}}(\mathrm{OH})^{2 \mathrm{x}}+\mathrm{Na}^{+}$
$\mathrm{C}_{\mathrm{x}} \mathrm{SO}_{3} \mathrm{Na}+\mathrm{H}^{+}$
$\mathrm{CxSO}_{3} \mathrm{HNa}^{+}$

Under these conditions lead ions are expected to exchange as follows:
$2 \mathrm{C}_{\mathrm{x}} \mathrm{OH}^{+}+\mathrm{Pb}^{2+}$
$\mathrm{C}_{\mathrm{x}} \mathrm{OH}_{2}^{2+}+\mathrm{Pb}^{2+}$
$\left(\mathrm{C}_{\mathrm{x}} \mathrm{O}\right)_{2} \mathrm{~Pb}^{2+}+2 \mathrm{H}^{+}$
$2 \mathrm{C}_{\mathrm{x}} \mathrm{ONa}^{+}+\mathrm{Pb}^{2+}$
$\mathrm{C} \stackrel{\mathrm{x}}{\mathrm{ONa}}{ }_{2}^{2+}+\mathrm{Pb}^{2+}$
$2 \mathrm{C} \mathrm{SO}_{3} \mathrm{H}+\mathrm{Pb}^{2+}$
$\mathrm{C} \mathrm{O} \mathrm{Pb}^{2+}+2 \mathrm{H}^{+}$
$\left(\mathrm{C}_{\mathrm{x}} \mathrm{O}\right)_{2} \mathrm{~Pb}^{2+}+2 \mathrm{Na}^{+}$
$\mathrm{C} \mathrm{O} \mathrm{Pb}^{2+}+2 \mathrm{Na}^{+}$
$\left(\mathrm{C} \mathrm{SO}_{3}\right)_{2} \mathrm{~Pb}+2 \mathrm{H}^{+}$
$2 \mathrm{C}_{\mathrm{x}} \mathrm{SO}_{3} \mathrm{Na}+\mathrm{Pb}^{2+}$
$\left(\mathrm{C}_{\mathrm{x}} \mathrm{SO}_{3}\right)_{2} \mathrm{~Pb}+2 \mathrm{Na}^{+}$

\section{Adsorption isotherms}

Results for application of various isotherm models for adsorption by BTACC and CAC are given in Table 3. Reported adsorption capacities of various materials for $\mathrm{Pb}$ (II) are given in Table 4 .

The Langmuir equation was applied for adsorption equilibrium for both BTACC and CAC:

$$
C_{\mathrm{e}} / q_{\mathrm{e}}=1 / Q_{0} b+C_{\mathrm{e}} / Q_{0}
$$

where $C_{\mathrm{e}}$ is equilibrium concentration $\left(\mathrm{mg} \cdot \mathrm{L}^{-1}\right), q_{\mathrm{e}}$ is amount adsorbed at equilibrium (mg.g $\mathrm{g}^{-1}$ ) and $Q_{0}$ and $b$ are Langmuir constants related to adsorption capacity and energy of adsorption, respectively (Hall et al., 1966; Webber et al., 1974). The linear plots of $C_{\mathrm{e}} / q_{\mathrm{e}}$ vs. $C_{\mathrm{e}}$ showed that the experimental data fitted well and absorption obeys the Langmuir model for both BTACC and CAC (Fig. 7).
The Freundlich isotherm is represented by Eq. 2:

$$
\log _{10}(x / m)=\log K+1 / n \log _{10} C_{\mathrm{e}}
$$

where $C_{\mathrm{e}}$ is the equilibrium concentration $\left(\mathrm{mg} \cdot \mathrm{L}^{-1}\right)$ and $x / m$ is the amount adsorbed per unit weight of BTACC and CAC $\left(\mathrm{mg} \cdot \mathrm{g}^{-1}\right)$. Plots of $\log (x / \mathrm{m})$ vs. $\log C_{e}$ are linear for both BTACC and CAC (Fig. 8). The straight-line nature of the plots indicates that the process followed was of the Freundlich adsorption type; $K$ and $n$ values for both carbon sources were calculated from the intercepts and slopes, respectively, and are shown in Table 2 . The values of $1<n<10$ show favourable adsorption of $\mathrm{Pb}$ (II) on both BTACC and CAC (Guadalupe et al., 2008). The $K$ values for BTACC and CAC are very much

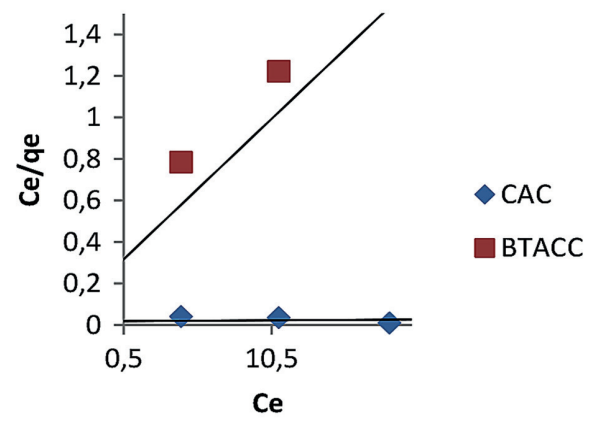

Figure 7. Langmuir adsorption isotherm for Pb (II) with BTACC and CAC system

Table 2. Comparison of $K$ and $n$ values in distilled water and tap water (Freundlich adsorption isotherm)

\begin{tabular}{lcclcl}
\hline \multirow{2}{*}{ Carbon } & \multicolumn{2}{c}{ Distilled water } & & \multicolumn{2}{c}{ Tap water } \\
\cline { 2 - 3 } \cline { 5 - 6 } & $\boldsymbol{K}$ & $\boldsymbol{n}$ & & $\boldsymbol{K}$ & \multicolumn{1}{c}{$\boldsymbol{n}$} \\
\hline BTACC & 31.62 & 1.15 & & 72.44 & 0.7518 \\
CAC & 0.3565 & 2.0 & & 19.05 & 2.82 \\
\hline
\end{tabular}

Table 3. Isothermal parameters for $\mathrm{Pb}$ (II) removal from aqueous solutions

\begin{tabular}{lccc}
\hline $\begin{array}{l}\text { Isotherm } \\
\text { model }\end{array}$ & Parameter & BTACC & CAC \\
\hline \multirow{3}{*}{ Freundlich } & $K\left(\mathrm{mg} \cdot \mathrm{g}^{-1}\right)$ & 31.62 & 0.3565 \\
& $n\left(\mathrm{mg} \cdot \mathrm{L}^{-1}\right)$ & 1.15 & 2.0 \\
& $R^{2}$ & 0.071 & 0.899 \\
\hline \multirow{2}{*}{ Langmuir } & $Q_{0}\left(\mathrm{mg} \cdot \mathrm{g}^{-1}\right)$ & 80 & 18.18 \\
& $b\left(\mathrm{mg} \cdot \mathrm{L}^{-1}\right)$ & 3.91 & 0.12 \\
& $R^{2}$ & 0.681 & 0.712 \\
\hline \multirow{3}{*}{ Temkin } & $A\left(\mathrm{~L} \cdot \mathrm{g}^{-1}\right)$ & 43.63 & 1.69 \\
& $B$ & 14.26 & 5.278 \\
& $R^{2}$ & 0.818 & 0.493 \\
\hline
\end{tabular}

Table 4. Adsorption capacities reported in the literature for $\mathrm{Pb}$ (II) adsorption

\begin{tabular}{llrl}
\hline $\begin{array}{l}\text { Agricultural } \\
\text { waste }\end{array}$ & $\begin{array}{l}\text { Adsorption } \\
\text { model }\end{array}$ & $\begin{array}{c}\text { Adsorption } \\
\text { capacity }\end{array}$ & References \\
\hline Cotton waste & Langmuir & $44.67 \mathrm{mg} \cdot \mathrm{g}^{-1}$ & Riaz et al., 2009 \\
Maize leaf & Freundlich & $4.356 \mathrm{mg} \cdot \mathrm{g}^{-1}$ & Babarinde et al., 2006 \\
Barley straws & Langmuir & $23.20 \mathrm{mg} \cdot \mathrm{g}^{-1}$ & Pehlivan et al., 2008 \\
Tamarind nut & Langmuir & $33.3 \mathrm{mg} \cdot \mathrm{g}^{-1}$ & Ramadevi et al., 2005 \\
Acacia catechu & Langmuir & $80 \mathrm{mg} \cdot \mathrm{g}^{-1}$ & Present study \\
& Freundlich & $31.62 \mathrm{mg} \cdot \mathrm{g}^{-1}$ & \\
\hline & & &
\end{tabular}




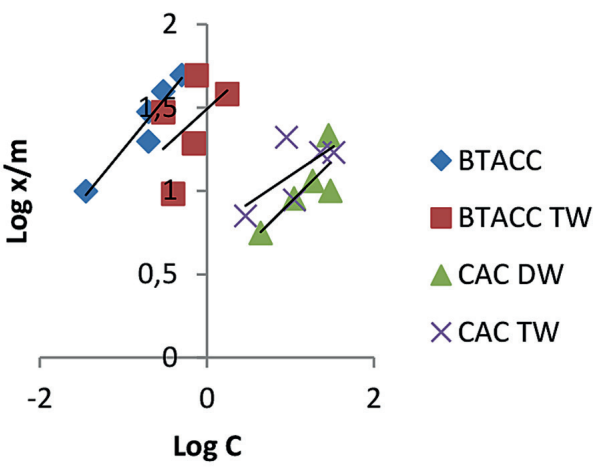

Figure 8. Freundlich adsorption isotherm for $\mathrm{Pb}$ (II) in distilled water (DW) and tap water (TW) for BTACC and CAC system

lower in distilled water than tap water because calcium and magnesium ions which are present in tap water compete for adsorption with lead.

\section{Temkin isotherm}

Temkin considered the effects of some implied adsorbentadsorbate interactions on the adsorption isotherms, suggesting that these interactions cause the heat of adsorption for all of the molecules in the layer to decrease linearly with the coverage. The Temkin isotherm has been applied in the following form (Mousavi et al., 2011):

$$
q_{e}=B_{\mathrm{T}} \ln K_{\mathrm{T}}+B_{\mathrm{T}} \ln C_{e}
$$

where $B_{\mathrm{T}}=R T / b_{\mathrm{T}}, T(\mathrm{~K})$ is the absolute temperature, $R$ is the universal gas constant $\left(8.314 \mathrm{~J} \cdot \mathrm{mol}^{-1} \mathrm{~K}^{-1}\right), K_{\mathrm{T}}\left(\mathrm{L} \cdot \mathrm{mg}^{-1}\right)$ is the equilibrium binding constant that corresponds to the maximum binding energy, $b_{\mathrm{T}}$ is the variation in the adsorption energy $\left(\mathrm{kJ} \cdot \mathrm{mol}^{-1}\right)$, and $B_{T}$ is a Temkin constant related to the heat of adsorption $\left(\mathrm{kJ} \cdot \mathrm{mol}^{-1}\right)$. The Temkin constants can be derived by plotting $q_{\mathrm{e}}$ versus $\ln C_{\mathrm{e}}$. Ho et al. (1996) indicated that the typical range for the binding energy during ion exchange mechanism is $8-16 \mathrm{~kJ} \cdot \mathrm{mol}^{-1}$. The heat of adsorption $B_{T}$ value for BTACC and CAC is 14.26 and $5.278 \mathrm{~kJ} \cdot \mathrm{mol}^{-1}$, respectively. It is confirmed that $\mathrm{BTACC}$ has the binding energy within the limit $8-16 \mathrm{~kJ} \cdot \mathrm{mol}^{-1}$ and it was found that the ion exchange mechanism took place while it further confirmed the ion exchange capacity value of BTACC. CAC, however, does not fall within the limit of binding energy $\left(8-16 \mathrm{~kJ} \cdot \mathrm{mol}^{-1}\right)$.

\section{Adsorption studies}

In order to explain the adsorption mechanism and ratecontrolling steps, the kinetic adsorption data were modelled using pseudo-first order and pseudo-second order kinetic equations.

\section{Pseudo-first order kinetics}

The pseudo-first order reaction equations of Lagergren (1898) have been widely used for the adsorption of liquid/solid systems on the basis of solid capacity. The linear form is generally expressed as:

$$
\log \left(q_{e}-q_{t}\right)=\log q_{e}-K_{1} t / 2.303
$$

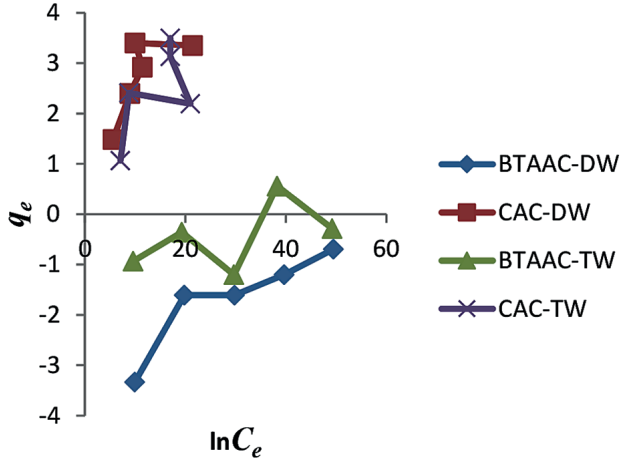

Figure 9. Temkin adsorption isotherm for $\mathrm{Pb}$ (II) in distilled water (DW) and tap water (TW) for BTACC and CAC system

where $q_{\mathrm{e}}\left(\mathrm{mg} \cdot \mathrm{g}^{-1}\right)$ and $q_{\mathrm{t}}\left(\mathrm{mg} \cdot \mathrm{g}^{-1}\right)$ are the amount of adsorption at equilibrium at time $t(\mathrm{~min}) ; k_{1}\left(\mathrm{~min}^{-1}\right)$ is the rate constant of the pseudo-first-order adsorption process. The values of $k_{1}, R^{2}$ and $q_{e}$ at different concentrations were obtained by plotting log $\left(q_{e}-q_{t}\right)$ versus $t$. The constants were determined experimentally by plotting of $\log (q e-q t)$ vs. $t$ (Fig 10a, b).

\section{Pseudo-second-order kinetics}

The pseudo-second-order model obtained from Ho et al. (1999) is based on the assumption that the adsorption follows the second-order rate equation. The linear form can be written as:

$$
t / q t=1 / K_{2} q_{\mathrm{e}}^{2}+\mathrm{t} / q t
$$

where $K_{2}$ is the rate constant of adsorption.

To evaluate the applicability of kinetic data relative deviation (P \%) was calculated using the equation:

$$
\mathrm{P} \%=1 / N \times 100\left(q_{e} \exp q_{e} \mathrm{cal} / q_{e} \mathrm{cal}\right)
$$

where $q_{\mathrm{e}(\exp )}$ and $q_{\mathrm{e}(\mathrm{cal})}$ are the experimental and calculated value of $\mathrm{Pb}$ (II) adsorbed on the adsorbents, $N$ is the number of measurements made. The lower the percentage deviation (P\%), the better is the fit. When $\mathrm{P}(\%)$ is less than 5 , the fit is considered to be excellent (Ugurlu et al., 2009). The correlation coefficient $\left(R^{2}\right)$ for the pseudo-second-order model is much closer to unity. The calculated $q_{e}$ value was much closer to the experimental $q_{e}$ value. All kinetic parameters and correlation coefficients are listed in Table 5. Also the percentage relative deviation ( $\mathrm{P} \%)$ was found to be less than $5 \%$ in the case of pseudo-secondorder. These values predict that the adsorption kinetics of $\mathrm{Pb}$ (II) ions onto the BTACC and CAC is mainly based on the pseudo-second-order equation. So the overall rate of $\mathrm{Pb}$ (II) ion adsorption may be controlled by the chemical process.

\section{Adsorption mechanism}

The pseudo-first-order and pseudo-second-order kinetic models were not able to explain the diffusion mechanism and also the rate-determining step for the adsorption of $\mathrm{Pb}$ (II) ions onto the BTACC and CAC. This is explained by the intraparticle diffusion model. For a solid-liquid sorption process, the solute transfer is usually characterized by either external mass transfer or intra-particle diffusion or both. During the 
adsorption of $\mathrm{Pb}$ (II) ions onto BTACC and CAC, the following three consecutive steps were involved (Acharya et al., 2009):

- The movement of adsorbate molecules from the bulk solution to the external surface of the adsorbent (film diffusion)

- Adsorbate molecules move to the interior part of the adsorbent particles (intra-particle diffusion)

- Sorption of the solute on the interior surface of the pores and capillary spaces of adsorbent (sorption)

The effects of contact time data were analysed by the Weber et al. (1963) intra-particle diffusion model to elucidate the diffusion mechanism; the model is expressed as:

$$
q_{t}=k_{\mathrm{d}} t^{1 / 2}+I
$$

where $I\left(\mathrm{mg} \cdot \mathrm{g}^{-1}\right)$ is the intercept and $k_{\mathrm{d}}$ is the intra-particle diffu-

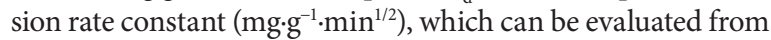
the slope of the linear plot of $q_{t}$ versus $t^{1 / 2}$ as shown in Figs 10e and $10 f$. The dual nature of the curve was obtained due to the varying extent of adsorption in the initial and final stages of the adsorption

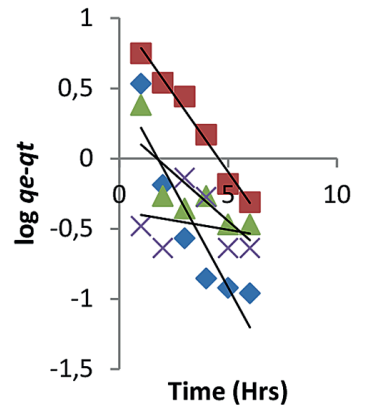

(a)

$\checkmark 10 \mathrm{ppm}$

-7ppm

$\triangle 5 \mathrm{ppm}$

$\times 3 p p m$

Time (Hrs)

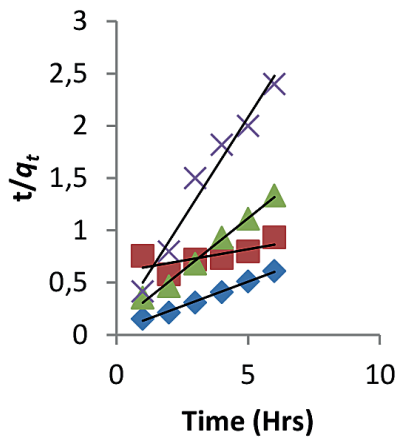

(c)

$\rightarrow 10 p p m$

$7 \mathrm{ppm}$

$\triangle 5 p p m$

$\times 3 p p m$

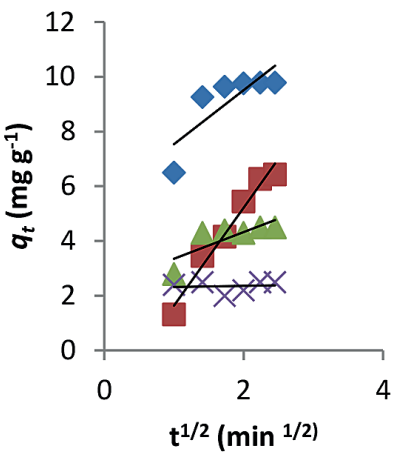

(e) experiment. This can be attributed to the fact that in the initial stages the sorption was due to the boundary layer diffusion effect whereas in the later stages (linear portion of the curve) it was due to the intra-particle diffusion effect. The intercept of the plot shows the boundary layer effect. The larger the intercept the greater will be the contribution of the surface sorption in the rate-controlling step. If the regression in the plot of $q_{\mathrm{t}}$ versus $t^{1 / 2}$ is linear and passes through the origin, then intra-particle diffusion is the sole ratelimiting step. However, in the present study, the plots were not linear and did not pass through the origin. The results show that intra-particle diffusion was not only the rate-limiting step, but also the rate-controlling step of adsorption.

\section{Film and pore diffusion coefficient}

For the adsorption of heavy metals on carbon surfaces, Michaelson et al., (1975) proposed film diffusion to be the ratedetermining process, and the value of film diffusion co-efficient $\left(D_{\mathrm{f}}\right)$ to be between $10^{-6}$ and $10^{-8} \mathrm{~cm}^{2} \cdot \mathrm{s}^{-1}$. If the pore diffusion were

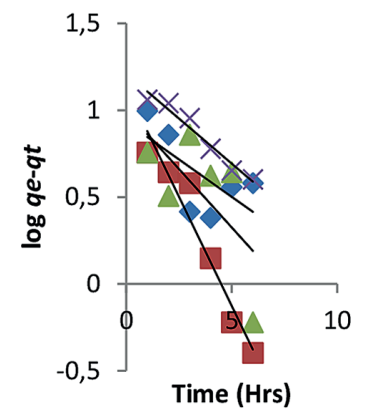

(b)

$\wedge 10 \mathrm{ppm}$

7ppm

$\triangle 5 p p m$

$\times 3 p p m$

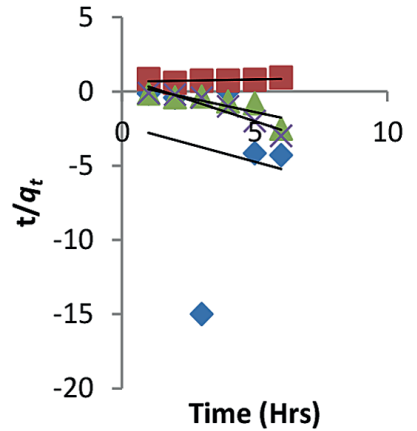

(d)

$\diamond 10 p p m$

$\square \mathrm{ppm}$

$\triangle 5 p p m$

$\times 3 p p m$

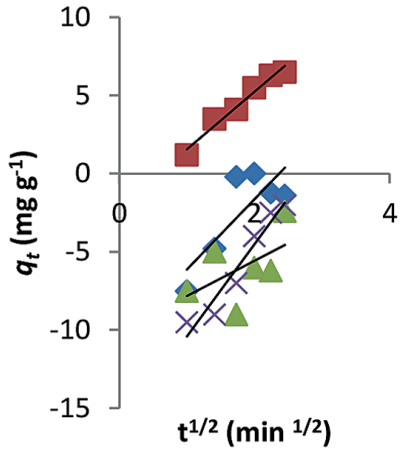

(t)

10ppm

7ppm

$\triangle 5 p p m$

$\times 3 p p m$

Figure 10. Adsorption studies for the Pb (II) ions adsorbed on BTACC and CAC: pseudo-first-order (a-b); pseudo-second-order (c-d); intradiffusion model (e-f) 
Table 5. Pseudo-first-order, pseudo-second-order and intra-particle diffusion model parameters for the adsorption of Pb (II) ions onto BTACC and CAC at different initial concentrations

\begin{tabular}{|c|c|c|c|c|c|c|c|c|c|}
\hline \multirow{3}{*}{ Kinetic model } & \multirow{3}{*}{ Parameters } & \multicolumn{8}{|c|}{ Concentrations $\left(\mathrm{mg} \cdot \mathrm{L}^{-1}\right)$} \\
\hline & & \multicolumn{4}{|c|}{ BTACC } & \multicolumn{4}{|c|}{ CAC } \\
\hline & & 10 & 7 & 5 & 3 & 10 & 7 & 5 & 3 \\
\hline \multirow{4}{*}{$\begin{array}{l}\text { Pseudo-first } \\
\text { order }\end{array}$} & $q_{\mathrm{e}} \exp \left(\mathrm{mg} \cdot \mathrm{g}^{-1}\right)$ & 9.91 & 6.93 & 4.84 & 2.73 & 2.4 & 6.9 & 1.8 & 2.0 \\
\hline & $\begin{array}{c}k_{1} \\
\left(\min ^{-1}\right)\end{array}$ & 0.284 & 0.112 & 0.135 & 0.026 & 0.086 & 0.251 & 0.134 & 0.103 \\
\hline & $q_{\mathrm{e}} \mathrm{cal}\left(\mathrm{mg} \cdot \mathrm{g}^{-1}\right)$ & 3.17 & 4.49 & 1.71 & 2.37 & 8.55 & 13.49 & 9.93 & 16.26 \\
\hline & $R^{2}$ & 0.839 & 0.686 & 0.641 & 0.652 & 0.530 & 0.843 & 0.624 & 0.856 \\
\hline \multirow{3}{*}{$\begin{array}{l}\text { Pseudo- } \\
\text { second order }\end{array}$} & $\mathrm{q}_{\mathrm{e}} \mathrm{cal}\left(\mathrm{mg} \cdot \mathrm{g}^{-1}\right)$ & 10.75 & 22.73 & 4.98 & 2.53 & 2.06 & 32.26 & 2.62 & 1.72 \\
\hline & $k_{2}\left(\mathrm{~g} \cdot \mathrm{mg}^{-1} \cdot \mathrm{min}^{-1}\right)$ & 2.27 & 0.07 & 1.89 & 0.01 & 0.21 & 0.05 & 0.72 & 0.64 \\
\hline & $R^{2}$ & 0.99 & 0.95 & 0.99 & 0.97 & 0.925 & 0.93 & 0.93 & 0.94 \\
\hline \multirow{3}{*}{$\begin{array}{l}\text { Intraparticle } \\
\text { diffusion }\end{array}$} & $K_{d}\left(\mathrm{mg} \cdot \mathrm{g}^{-1} \cdot \mathrm{min}^{-1 / 2}\right)$ & 1.976 & 3.580 & 0.974 & 0.041 & 4.489 & 3.681 & 2.252 & 5.898 \\
\hline & $I\left(\mathrm{mg} \cdot \mathrm{g}^{-1}\right)$ & 5.559 & 1.946 & 2.374 & 2.276 & 10.62 & 2.129 & 10.08 & 16.31 \\
\hline & $R^{2}$ & 0.668 & 0.975 & 0.635 & 0.011 & 0.654 & 0.970 & 0.291 & 0.939 \\
\hline Film diffusion & $D_{f}\left(\mathrm{~cm}^{2} \cdot \mathrm{s}^{-1}\right)$ & $8.08 \times 10^{-6}$ & $4.55 \times 10^{-6}$ & $1.44 \times 10^{-6}$ & $3.45 \times 10^{-6}$ & $1.03 \times 10^{-6}$ & $3.47 \times 10^{-6}$ & $7.44 \times 10^{-6}$ & $6.29 \times 10^{-6}$ \\
\hline Pore diffusion & $D_{\mathrm{p}}\left(\mathrm{cm}^{2} \cdot \mathrm{s}^{-1}\right)$ & $2.79 \times 10^{-6}$ & $1.75 \times 10^{-5}$ & $1.79 \times 10^{-5}$ & $1.08 \times 10^{-5}$ & $1.23 \times 10^{-5}$ & $1.89 \times 10^{-5}$ & $1.07 \times 10^{-5}$ & $1.18 \times 10^{-5}$ \\
\hline
\end{tabular}

to be the rate-limiting factor, the pore diffusion co-efficient $(D p)$ should be in the range of $10^{-11}-10^{-13} \mathrm{~cm}^{2} \cdot \mathrm{s}^{-1}$ (Senthil Kumar et al., 2009). Assuming a spherical geometry for the sorbents, the theoretical rate constant of the process can be correlated to the pore diffusion co-efficient in accordance with the expression:

$$
\begin{aligned}
& t_{1 / 2}=0.03 r_{0}^{2} / D_{p} \\
& t_{1 / 2}=0.23 r_{0}^{\delta} \mathrm{c}^{\wedge} / \mathrm{c} D_{f}
\end{aligned}
$$

where $r_{0}$ is the radius of the sorbent expressed in $\mathrm{cm}^{2}, D_{\mathrm{p}}$ is the pore diffusion coefficient expressed in $\mathrm{cm}^{2} \cdot \mathrm{s}^{-1}, D_{f}$ the film diffusion co-efficient expressed in $\mathrm{cm}^{2} \cdot \mathrm{s}^{-1}, \mathrm{c}^{1} / \mathrm{c}$ is the equilibrium loading factor of the sorbent and $t_{1 / 2}$ is the half-life period expressed in seconds. The results for BTACC and CAC are given in Table 5.

\section{CONCLUSION}

The present investigation showed that carbon prepared from a novel waste material, BTACC, is able to remove of $98 \% \mathrm{~Pb}$ (II) ion from aqueous solution, whereas CAC removed only $52 \%$. The presence of hydroxyl, carboxylic and sulphonic acid groups in BTACC was confirmed by FT-IR spectroscopy, and give ion exchange properties to the BTACC. The ion exchange value of BTACC was found to be 0.6024 molar equiv. ${ }^{-1}$. Compared with $\mathrm{CAC}$, which has a very narrow range of $\mathrm{pH} 5, \mathrm{BTACC}$ as a wider applicable $\mathrm{pH}$ range from $4-10$ where the carbon is applied in wastewater treatment. The equilibrium data agreed well with the Langmuir adsorption value. The sorption kinetic pseudo-second-order model and intraparticle diffusion is not the sole rate-controlling factor. The value of the film diffusion co-efficient obtained for BTACC and CAC lies between $10^{-6}$ to $10^{-8} \mathrm{~cm}^{2} \cdot \mathrm{s}^{-1}$ for various initial concentrations of $\mathrm{Pb}$ (II) ions. Hence it is evident that $\mathrm{Pb}$ (II) removal follows film diffusion which is the rate-limiting factor. Therefore, it can be concluded that carbon derived from BTACC is very effective for the removal of $\mathrm{Pb}$ (II) from aqueous solution.

\section{ACKNOWLEDGEMENTS}

The authors are very thankful to Dr A Elango ME, Ph.D, Principal, Alagappa Chettiar College of Engineering and
Technology, Karaikudi for providing necessary facilities and encouragement to complete this work. We also thank the management of CMS College of Engineering and Technology, Coimbatore for their constant support.

\section{REFERENCES}

ABBASZADEH S, RAFIDAH WAN ALWI S, WEBB C, GHASEMI N and MUHAMAD II (2016) Treatment of lead-contaminated water using activated carbon adsorbent from locally available papaya peel biowaste. J. Clean. Prod. 118 210-222. https://doi.org/10.1016/j. jclepro.2016.01.054

ACHARYA J, SAHU JN, MOHANTY CR and MEIKAP BC (2009) Removal of lead (II) from wastewater by activated carbon developed from tamarind wood by zinc chloride activation. Chem. Eng. J. 149 249-262. https://doi.org/10.1016/j.cej.2008.10.029

AHAMED M, VERMA S, KUMAR A and SIDDIQUI MKJ (2005) Environmental exposure to lead and its correlation with biochemical indices in children. Sci. Total Environ. 346 48-55. https://doi.org/10.1016/j.scitotenv.2004.12.019

APHA, AWWA (1973) Standard Methods for the Examination of Water and Wastewater. American Public Health Association, Washington D.C.

BABARINDE NAA, BABALOLA JO and SANNI RA (2006) Biosorption of lead ions from aqueous solution by maize leaf. Int. J. Phys. Sci. 1 23-26.

DEMIRBAS A (2008) Heavy metal adsorption onto agro-based waste materials: A review. J. Hazardous Mater. 157 220-229. https://doi. org/10.1016/j.jhazmat.2008.01.024

GOEL J, KADIRVELU K, RAJAGOPAL C and KUMAR GARG V (2005) Removal of lead (II) by adsorption using treated granular activated carbon, batch and column studies. J. Hazardous Mater. 125 211-220. https://doi.org/10.1016/j.jhazmat.2005.05.032

GROFFMAN A, PETERSON S and BROOKINS D (1992) Removing lead from wastewater using zeolite. Water Environ. Technol. 4 54-59.

GUADALUPE R, REYNEL-AVILA HE, BONILLA-PETRICIOLET A, CANO-RODRÍGUEZ I, VELASCO-SANTOS C and MARTÍNEZ HERNÁNDEZ AL (2008) Recycling poultry feathers for $\mathrm{Pb}$ removal from wastewater: kinetic and equilibrium studies. Int. J. of Chem. Molec. Eng. 2 (11) 338-346.

HALL KR, EAGLETON LC, ACRIVOS A and VERMEULEN TH (1966) Pore- and solid-diffusion kinetics in fixed-bed adsorption under constant-pattern conditions. Fund. Ind. Eng. Chem. 5 212-223. https://doi.org/10.1021/i160018a011

HO YS and MCKAY G (1999) Pseudo-second order model for sorption processes. Process Biochem. 34 451-465. https://doi.org/10.1016/ s0032-9592(98)00112-5

HO YS, WASE DAJ and FORSTER CF (1996) Removal of lead ions 
from aqueous solution using sphagnum moss peat as adsorbent. Water SA 22 219-224.

HUA M, ZHANG S, PAN B, ZHANG W, LU LV and ZHANG Q (2012) Heavy metal removal from water/wastewater by nanosized metal oxides: A review. J. Hazardous Mater. 211 317- 331. https://doi. org/10.1016/j.jhazmat.2011.10.016

INGLEZAKIS VJ, LOIZIDOU MD and GRIGOROPOULOU HP (2003) Ion exchange of $\mathrm{Pb}^{2+}, \mathrm{Cu}^{2+}, \mathrm{Fe}^{3+}$ and $\mathrm{Cr}^{3+}$ on natural clinoptilolite: selectivity determination and influence of acidity on metal uptake. J. Colloid Interf. Sci. 261 49-54. https://doi. org/10.1016/s0021-9797(02)00244-8

JYOTIKUSUM A, SAHU JN, MOHANTY CR and MEIKAP BC (2009) Removal of lead (II) from wastewater by activated carbon developed from tamarind wood by zinc chloride activation. Chem. Eng. J. 149 249-262. https://doi.org/10.1016/j.cej.2008.10.029

KADIRVELU K, THAMARAISELVI K and NAMASIVAYAM C (2001) Removal of heavy metals from industrial wastewaters by adsorption onto activated carbon prepared from an agricultural solid waste. Bioresour. Technol. 76 63-65. https://doi.org/10.1016/ s0960-8524(00)00072-9

LAGERGREN S (1898) About the theory of so-called adsorption of solute substances. Kungliga Svenska Vetenskapsakad Handlingar 24 1-39.

MICHELSON LD, GIDEON PG, PACE EG and KUTAL LH (1975) US Department of Industry, Office of Water Research and Technology, Bulletin 74.

MOUSAVI HZ and SEYEDI SR (2011) Nettle ash as a low cost adsorbent for the removal of nickel and cadmium from wastewater. Int. J. Environ. Sci. Technol. 8 (1) 195-202. https://doi.org/10.1007/ bf03326209

PATHANIA D, SHARMA S and SINGH P (2017) Removal of methylene blue by adsorption onto activated carbon developed from Ficus carica bast. Arab. J. Chem. 10 1445-1451. https://doi. org/10.1016/j.arabjc.2013.04.021

PEHLIVAN E, ALTUN T and PARLAYICI S (2008) Utilization of barley straws as biosorbents for $\mathrm{Cu}^{2+}$ and $\mathrm{Pb}^{2+}$ ions. J. Hazardous Mater. http://dx.doi.org/10.1016/j.jhazmat, 08.115.

RAUNIO S and TAHATI H (2001) Glutamate and calcium uptake in astrocytes after acute lead exposure. Chemosphere 44 355-359. https://doi.org/10.1016/s0045-6535(00)00305-2

RIAZA M, NADEEMA R, HANIFA MA, ANSARIC TM and REHMANA K (2009) $\mathrm{Pb}(\mathrm{II})$ biosorption from hazardous aqueous streams using Gossypium hirsutum (cotton) waste biomass. J. Hazardous Mater. 161 88-94.

SENTHIL KUMAR P and GAYATHRI R (2009) Adsorption of $\mathrm{Pb}^{2+}$ ions from aqueous solutions onto bael tree leaf powder. J. Eng. Sci. Technol. 4 381-399.

SRINIVASAN K and RAMADEVI A (2005) Removal of lead in aqueous medium by tamarind nut carbon. Ind. J. Environ. Protect. 25 420-428.

SURESH JEYAKUMAR RP and CHANDRASEKARAN V (2014) Adsorption of lead (II) ions by activated carbons prepared from marine green algae. Int. J. Ind. Chem. 5 (2) 1-10. https://doi. org/10.1007/s40090-014-0010-z

THARANITHARAN V and SRINIVASAN K (2009) Studies on the adsorption of $\mathrm{Ni}$ (1l) on to modified amberlite XAD-7HP resin. Ind. J. Environ. Protect. 29 (4) 294.

UGURLU M, KULA I, HAMDI KARAOGLU M and ARSLAN Y (2009) Removal of $\mathrm{Ni}(\mathrm{II})$ ions from aqueous solutions using activated carbon prepared from olive stone by $\mathrm{ZnCl}_{2}$ activation. Environ. Progress Sustainable Energ. 28 547-557. https://doi. org/10.1002/ep.10358

WEBBER TN and CHAKRAVARTI RK (1974) Pore and solid diffusion models for fixed bed adsorbers. Am. Inst. Chem. Eng. 20 228-238. https://doi.org/10.1002/aic.690200204

WEBER WJ and MORRIS JC (1963) Kinetics of adsorption on carbon from solution. J. Sanit. Eng. Div. 89 31-60.

WHO (World Health Organization) (1977) Environmental Health Criteria, 3, Lead. WHO, Geneva. 